\title{
CURRICULUM REFORM IN SCOTTISH EDUCATION: DISCOURSE, NARRATIVE AND ENACTMENT
}

\section{WALTER HUMES AND MARK PRIESTLEY}

\section{ABSTRACT:}

This chapter examines curriculum reform in Scotland, showing how the ambitious aspirations of its flagship policy, Curriculum for Excellence, were subject to a complex array of global, national and local pressures and had to take account of political and cultural circumstances that posed particular challenges. Both the Scottish Government's management of the reform programme and the teaching profession's response to it are subject to detailed scrutiny. The discussion pays particular attention to the discourse used in promoting the policy, the shifting nature of the official narrative as the recommendations of international agencies were taken on board, and the issues that arose as the policy moved from intention to enactment. Drawing on the notion of 'curriculum making', which serves as a conceptual thread for all the contributions to this volume, the analysis highlights both evidence of progress and sites of continuing debate.

\section{KEYWORDS:}

(Please supply up to 6 keywords for your Chapter)

1. Curriculum for Excellence

2. Policy process

3. Curriculum change

4. Curriculum making

5. Curriculum enactment

6. Scotland 
Humes, W. \& Priestley, M. (2021). Curriculum reform in Scottish Education: Discourse, Narrative and Enactment. In: M. Priestley, D. Alvunger, S. Philippou. \& T. Soini, Curriculum making in Europe: policy and practice within and across diverse contexts. Bingley: Emerald.

\section{Introduction}

Scotland was an early starter in the post-millennial international trend to reform the school curriculum. Its Curriculum for Excellence (CFE) programme, first launched in 2004, is an archetypal example of the 'new curriculum' model documented by Priestley and Biesta (2013). CfE was first set out as a broad statement of principles, subsequently developed and elaborated in the years that followed (Humes, 2013; Priestley, 2018a). The curriculum manifests many of the common goals (school improvement; equity; a future focus; and coherence) and emphases (competencies; values; pedagogy; student agency; partnerships; and reduced prescription) identified by Sinnema and Aitken (2013) in their analysis of international curricular commonalities. Its key features include: an increased emphasis on generic skills at the expense of the specification of propositional knowledge; so-called 'progressive' and active pedagogy, placing the learner centre-stage; a description of the learning process in terms of "experiences" and "outcomes", set out in a framework of linear levels; an aspiration that teachers would become curriculum developers and change agents; and above all, a desire to promote four generic "capacities" (successful learners, confident individuals, effective contributors, responsible citizens).

This chapter will examine the diverse influences which caused the reform programme to be formulated in this way, the political, structural and cultural context which it had to negotiate, the professional response by teachers and other stakeholders, and the adjustments that had to be made at national, local, school and classroom levels as the reforms were developed and implemented. These features serve to illustrate the inadequacy of simple linear models of change. As Ball (1990, p. 3) has observed, at best the policy-making process is likely to be "unwieldy and complex", at worst "unscientific and irrational". Particular attention will be given to the discourse used to promote the reforms, to the official narrative contained in policy documents, and to the discontinuities between intention and enactment.

The chapter, in common with other contributions to this book, examines these issues within an ecology of layered curriculum making. We analyse how national policy framing (macro-level curriculum making) has been influenced by supra-level discourses, including the role of the OECD (which has carried out reviews of Scottish education) and the International Council of Educational Advisers (ICEA) set up by the Scottish Government in 2016 to make recommendations for improvement. We explore meso-level curriculum making and its role in the implementation of CfE. In 
Humes, W. \& Priestley, M. (2021). Curriculum reform in Scottish Education: Discourse, Narrative and Enactment. In: M. Priestley, D. Alvunger, S. Philippou. \& T. Soini, Curriculum making in Europe: policy and practice within and across diverse contexts. Bingley: Emerald.

Scotland, meso-layer activity comprises guidance, support and quality assurance undertaken by 32 local authorities and national organizations such as Education Scotland (the key agency of government in relation to curriculum, quality and improvement); latterly, in 2018, six Regional Improvement Collaboratives (RICs) were established to complement these bodies. We also discuss how curriculum making has occurred in micro-level settings - schools and other educational contexts - in relation to CfE. Where possible, we draw upon empirical research to support our conclusions, although we note at the outset that independent research (for example, by academics) has been limited, despite the undoubted importance of the curriculum to Scottish education.

Scotland, like many other countries, has been subject to global pressures deriving from economic priorities (market growth, skills development, employee flexibility, managerial accountability). Within education, these have been interpreted and mediated through well-established national institutions and a powerful educational policy community. A shifting policy discourse (excellence, equity, collaboration, empowerment, attainment, leadership) and the persistence of tensions resulting from accountability mechanisms have made the enactment of CfE challenging for many teachers. Especially in the early stages, there was limited opportunity to engage in "sense making" and "capacity building" which are essential requirements of successful reforms (Priestley \& Drew, 2017). More recently, there have been a number of developments aimed at promoting fruitful dialogue and the sharing of good practice among stakeholders. These include a report by the ICEA following concerns about a perceived decline in educational standards (ICEA, 2018), and a "refreshed" narrative for CfE, introduced in 2019 following a recommendation in the 2015 OECD report on CFE (OECD, 2015). These issues and developments will feature in the account that follows, with particular attention being given to the ICEA report and the "refreshed" CfE narrative. We commence this discussion with a summary of the national context for curriculum reform.

\section{Scottish Context}

Understanding the unique political and cultural context of the Scottish experience is important. Scotland has a proud educational tradition (quite distinct from that of England and the rest of the UK). Since 2007 it has been governed by the Scottish National Party, which has as its principal aim the creation of an entirely independent Scotland. There is also considerable cultural diversity within the country, with sparsely populated areas in the highlands and islands contrasting with the predominantly urban character of the central belt, most evident in the major cities of Glasgow and Edinburgh. International, national and local factors have been involved in framing, disseminating, 
Humes, W. \& Priestley, M. (2021). Curriculum reform in Scottish Education: Discourse, Narrative and Enactment. In: M. Priestley, D. Alvunger, S. Philippou. \& T. Soini, Curriculum making in Europe: policy and practice within and across diverse contexts. Bingley: Emerald.

interpreting and implementing the educational reform programme, a process that has revealed what have been called "complex webs of enactment" (Priestley \& Philippou, 2018). The ICEA report recognizes the political ambition to make Scottish education "world class", but advises that it should remain "uniquely and appropriately Scottish".

Scotland's programme of educational reform, at one level, is an expression of a global movement to reshape public understanding of the knowledge, skills and dispositions which are required in the twenty-first century. This movement operates above the level of nation states and involves complex networks of politicians, businesses, philanthropic organizations and private consultants (Ball, 2012). Although the outward form of Scottish education has not been subject to the degree of change evident, for example, in England (with its academies run by private trust companies independent of local authorities), some of the justifications for the flagship CfE policy have drawn on debates and policy documents produced by supra-level international bodies such as the Organization for Economic Cooperation and Development (OECD).

These influences are threefold. First, supra- or trans-national discourses of education provide justifications for national policy, including: the need to respond to environmental, social, economic and technological challenges (e.g. see: OECD 2018). Second, Scotland, in common with other countries, is subject to PISA shock in the face of declining scores (comparative and absolute) in PISA tests $^{1}$. Third, Scotland has commissioned country reviews by the OECD $\left(2007 ; 2015^{2}\right)$, which have emphasized certain themes pertinent to curriculum development: in 2007, in relation to equity (Raffe, 2008); and in 2015 calling for better enactment to close an implementation gap, a "strengthened middle" tier to support curriculum development in schools, and the development of a new "simplified narrative" for the curriculum. As we shall explore, these have influenced subsequent curriculum making.

The influence of supra-level discourses can be seen in the language of education policy (Reeves, 2008; Priestley \& Biesta, chapters 1 and 2), often exhibiting tensions between different discourses. On the one hand, policy emphasizes the necessity of ensuring a more skilled, flexible and competitive workforce, and the importance of leadership, targets, audits and accountability in driving improvements (Scottish Government, 2016). Running alongside this hard-edged managerial language

\footnotetext{
${ }^{1}$ Some commentators, for example, Professor Lindsay Paterson, blame CfE for declining PISA scores: https://blogs.Ise.ac.uk/politicsandpolicy/curriculum-for-excellence/.

${ }^{2}$ In February 2020, following a vote in the Scottish Parliament, the SNP government was obliged to launch a further comprehensive review of the curriculum, to be undertaking by the OECD, and to report in February 2021.
} 
Humes, W. \& Priestley, M. (2021). Curriculum reform in Scottish Education: Discourse, Narrative and Enactment. In: M. Priestley, D. Alvunger, S. Philippou. \& T. Soini, Curriculum making in Europe: policy and practice within and across diverse contexts. Bingley: Emerald.

is a softer form of discourse promoting professional autonomy, ownership and empowerment, designed to appeal to the teachers charged with the task of responding to the proposed reforms. Some of the tensions that can arise from the attempt to reconcile a neo-liberal culture of performativity with claims that new approaches open up the possibility of greater professional freedom will become apparent later in the chapter.

Educational reform in Scotland also needs to be set against the country's unique political context. A separate Scottish Parliament, with significant devolved powers within the United Kingdom, was established in 1999. A distinctive educational system in Scotland was already well established prior to devolution (see Humes and Bryce, 2018). Since 2007, the Scottish National Party (SNP), which has as its principal aim the creation of an entirely independent country, has formed the government. A referendum on independence in 2014 led to a 55\% to $45 \%$ vote in favour of remaining part of the UK. In the 2016 referendum on membership of the European Union, Scotland voted strongly in favour of continuing membership, while the UK as a whole voted to leave, thus creating ongoing tension between the Scottish and UK Parliaments. Following a period of political stalemate and then a decisive general election victory for the Conservative Party in December 2019, the UK formally left the EU in January 2020, though with many issues still to be negotiated. The Scottish Government has demanded a second referendum on independence. This would require agreement from the UK parliament in London, which has not been forthcoming, ensuring that the dispute will feature strongly in the 2021 elections to the Scottish Parliament. If the SNP is re-elected in 2021, the campaign for a second referendum on independence is likely to intensify.

\section{Curriculum for Excellence (CfE): The Complexity of Managing Change}

Unsurprisingly, the development of such an ambitious programme as CfE was not without problems of various kinds - intellectual, managerial and operational (Priestley \& Humes, 2010; Humes, 2013; Priestley, 2018a). A former senior official admitted in 2014 that a reform of the scale of CfE posed "very significant implementation challenges" (Donaldson, 2014, p. 188). Although there was substantial support among many teachers for the intentions behind the proposed reforms, a recurring criticism was that, despite extensive documentation and the provision of courses of professional development, the aim of bringing about a professional "transformation" had only partial success. A consideration of why this was the case raises interesting questions about impediments to reform and the complex journey between conception and enactment (Ball et al., 2012). CfE has shown that the making of policy needs to be viewed through a number of lenses - historical legacy, professional 
Humes, W. \& Priestley, M. (2021). Curriculum reform in Scottish Education: Discourse, Narrative and Enactment. In: M. Priestley, D. Alvunger, S. Philippou. \& T. Soini, Curriculum making in Europe: policy and practice within and across diverse contexts. Bingley: Emerald.

ideology, discursive shifts and teacher agency. This is consistent with Broadhead's account of the reform of the Norwegian curriculum, in which history, politics and personal narratives all contributed to the shaping of policy and practice (Broadhead, 2002).

For two decades prior to the introduction of CfE, curriculum reform in Scotland had become increasingly centralist, with one commentator referring to the "new authoritarianism" of the 1980s (Gatherer, 1988) and others detecting an intensification of this trend when the National Guidelines for the 5-14 programme were introduced in 1993 (Roger and Hartley, 1990). Although these "guidelines" did not have the statutory force of the National Curriculum in England, introduced in 1988, they were treated as mandatory and teachers were encouraged to follow them without question. Objections that this would lead to a diminished teaching force, with staff becoming compliant technicians rather than thinking professionals, were disregarded. Against this background, the expectation that teachers could adopt a different mindset under $\mathrm{CfE}$, contributing to the development of the programme and being given more scope for professional judgement, was decidedly optimistic. What was being asked was a complete change of culture, a transition that could not simply be willed. It would take time and would depend on the emergence of a climate of trust between policy makers and practitioners. It would also involve a challenge to traditional hierarchies and to previously uncontested notions of what "professionalism" entails.

This goes some way towards explaining the uneven development of CfE during its early stages. In a study of how Scottish teachers made sense of the new curriculum, Priestley and Minty (2013) drew a distinction between "first order" and "second order" engagement with the programme. The former refers to whether or not teachers welcomed, in general terms, the overall philosophy of CfE, while the latter refers to the extent to which teachers engaged, at a deep level, with the underpinning ideas of the new curriculum, as well as the extent to which the CfE approach was congruent with their own implicit theories of knowledge and learning. The findings suggested some tensions between the two. While most teachers in the study welcomed the general approach of $\mathrm{CfE}$, they did not all subscribe to the largely constructivist view of knowledge and learning which was implicit in its recommendations. Secondary teachers in particular were inclined to retain transmissionist views of knowledge and learning, viewing their role as the "delivery" of content. There were similar tensions in teacher attitudes to the relative freedom which CfE seemed to offer. While a move away from the "regimentation" of 5-14 was welcomed, many teachers still looked for reassurance that they were doing the right thing. The researchers concluded: "Despite CfE positioning teachers as agents of change, our interview data show that many teachers are not yet ready for such a sudden shift from prescription to autonomy" (Priestley and Minty, 2013: 47). 
Humes, W. \& Priestley, M. (2021). Curriculum reform in Scottish Education: Discourse, Narrative and Enactment. In: M. Priestley, D. Alvunger, S. Philippou. \& T. Soini, Curriculum making in Europe: policy and practice within and across diverse contexts. Bingley: Emerald.

\section{Policy Transmission: (Re-)interpretation and Resistance}

The production of a policy document proposing a major curricular reform is merely the first stage of a complex process which operates at different levels, in diverse contexts, involving a range of actors of varying seniority and influence. In the case of $\mathrm{CFE}$, following the publication of the original policy document (Scottish Executive, 2004), a limited research and review exercise was initiated, with representatives from different sectors of the educational system, as well as inspectors, civil servants and staff from the national advisory body on curriculum, Learning and Teaching Scotland (which subsequently became Education Scotland). A substantial amount of additional documentation was produced, most notably a progress report (Scottish Executive, 2006a) and five publications each using a "building" metaphor, indicating that the reform programme was seen as a developmental project (Scottish Executive, 2006b, 2007; Scottish Government, 2008, 2009, 2011). These elaborations of the original ideas were produced partly in response to requests from teachers, but they introduced potential problems. A major issue lay in the multifarious functions of the documentation, which simultaneously provided a justificatory rhetoric for the new curriculum, guidance for implementation and conceptualization of key ideas. The documents failed to provide a single framework for the curriculum, as was the case, for example in the Junior Cycle reforms in Ireland ${ }^{3}$; instead, there were a lot of separate publications - the five BTC documents, the Experiences and Outcomes for eleven curriculum areas, a subsequent series of curriculum briefings, and so on. These publications offered practitioners a diffuse focus for engaging with $\mathrm{CFE}$, resulting in complexity and confusion, and a sense of "vagueness" (Priestley and Minty, 2013; Hizli Alkan and Priestley, 2019). Education Scotland, the national agency, responded with the publication of summaries of the BTC publications and the development of guidance and exemplars. Nevertheless, for teachers the experience of CfE was a confusing welter of documentation (a figure of 20,000 pages of guidance ${ }^{4}$, along with 1850 learning outcomes ${ }^{5}$ was commonly cited). Furthermore, the development of new guidance over time led to shifting emphases, uncertainties about certain key concepts (e.g. active learning, interdisciplinary learning), the scope for varied interpretations by the intended readership, and increased bureaucracy

\footnotetext{
${ }^{3}$ https://www.ncca.ie/media/3249/framework-for-junior-cycle-2015-en.pdf

${ }^{4}$ https://www.tes.com/news/inspection-body-closer-ever-teachers

${ }^{5}$ Cited in the OECD (2015 report)
} 
Humes, W. \& Priestley, M. (2021). Curriculum reform in Scottish Education: Discourse, Narrative and Enactment. In: M. Priestley, D. Alvunger, S. Philippou. \& T. Soini, Curriculum making in Europe: policy and practice within and across diverse contexts. Bingley: Emerald.

in schools. Some of these points were noted by the OECD in their 2015 review of the curriculum which called for a simplified narrative, a "strengthened middle" between macro and micro levels of policy, and better understanding of the complexities of curriculum enactment. The Scottish Government's subsequent response to these recommendations is a clear example of the way in which supra level influences can impact on national educational systems.

Critique of the proliferation of documentation prompted Education Scotland to remove many items from its website and issue a simplified Statement for Practitioners, highlighting the key messages and decrying unnecessary bureaucracy (Education Scotland, 2016). At this stage the government also published assessment benchmarks for each curriculum area, apparently in response to teacher demands for clearer guidance, but in effect introducing additional layers of complexity - a spiral of specification (Wolf, 1995) that has added thousands of new statements to the 1850 Experiences and Outcomes and done little to reduce the bureaucracy (see Priestley 2016). Moreover, interpretation of what is recommended is, to a significant extent, context dependent and subject to the personal philosophies of the recipients (Priestley, Biesta \& Robinson, 2015). Thus, education officials in local authorities, for example, are likely to focus on the managerial requirements necessary to promote, disseminate and embed the reform programme, while classroom teachers may be more inclined to consider how compatible the new ideas are with their own professional philosophy. Messages are also subject to mutation as they move from one context to other. This helps to explain what is often referred to as the "implementation gap" between policy intention and classroom practice. Teachers who are intent on resisting change have several strategies open to them. They could argue against it in professional forums and by writing to the press (the latter response carries risks in a hierarchical culture - e.g. see: Seith, 2018). They may pay lip service to the reform, adopting some of the approved discourse, but continue to use the same practices as before. Research by Priestley, Biesta and Robinson (2015) documented how experienced teachers assimilated CfE into their existing practices, describing them in the language of the new policy. Or they may make some superficial changes to their practices, without being committed to the underlying philosophy: this has been called "strategic compliance" (Priestley and Minty, 2013). All of these responses were in evidence during the roll out of the CfE programme.

Critique of CfE would be incomplete without mention of qualifications reform. Following fairly extensive consultation, new qualifications designed for CfE were announced in 2009 (for the background to these reforms, see: Kidner 2010). The main changes were: the replacement of standard grade and intermediate 1 and 2 qualifications by "National 4" and "National 5" qualifications; the revision of other National Qualifications to ensure that they articulate with CfE. This replaced a twin 
Humes, W. \& Priestley, M. (2021). Curriculum reform in Scottish Education: Discourse, Narrative and Enactment. In: M. Priestley, D. Alvunger, S. Philippou. \& T. Soini, Curriculum making in Europe: policy and practice within and across diverse contexts. Bingley: Emerald.

track of former qualifications used in schools, with a new unitary pathway, aligned with the Scottish Qualifications and Credit Framework ${ }^{6}$. The development of new qualifications has profoundly shaped the subsequent development of CfE. Arguably, they have come to define CfE in secondary schools, with a corresponding neglect of the Broad General Education phase in school years S1-3). They have also been associated with a narrowing of the senior phase curriculum. Formerly, Scottish students took typically 8 SCQF level 3, 4 or 5 qualifications over 2 years in S3 and S4; under the new system, the new qualifications at these levels are taken over a single year. This appears to be an unintended consequence of a decision taken early in the reform process to maintain the size of qualifications at 160 hours of study, meaning that there is simply less time available to fit in a range of qualifications, and in many schools, the choice of subjects has reduced from 8 to 7, 6 or even 5 . Criticisms that this trend is narrowing the curriculum are countered by assertions that the new qualifications were intended to engender flexibility of provision, with students able to choose a portfolio of qualifications at different levels over the full 3 years of the senior phase (from S4 to S6). In practice, however, many schools lack the resources to offer such flexibility. Additionally, many schools continue to see transitions across the SCQF levels in terms of a ladder of progression; it is not generally possible to undertake a level 6 Higher qualification in year S5, without having previously taken the same subject successfully at level 5 , and such decisions can be driven by accountability pressures, as schools are benchmarked according to their overall attainment. Moreover, there is some evidence that curriculum narrowing is socially stratified; that is, schools in comparatively disadvantaged areas are likely to offer their students a more restricted choice of study in S4. This is complicated and contested terrain, which has prompted a parliament enquiry, and currently research remains at an embryonic stage (see: Priestley, 2018b; Shapira and Priestley, 2018, 2019).

\section{The ICEA Report (2018)}

The global framing of Scottish education was reinforced in 2016 with the appointment of an International Council of Educational Advisers to make recommendations to the Scottish Government about the future direction of policy. In effect, this involved a combination of supra- and macro-levels of influence. The Council consisted of recognized experts from Europe, North America, Asia and the United Kingdom, though its capacity to give genuinely independent advice was called into question on the grounds that certain members had previously received awards from the Scottish Government (Blackburn \& McEnaney, 2017). The "political" aspects of policy development can never be entirely

\footnotetext{
${ }^{6}$ See https://scaf.org.uk/
} 
Humes, W. \& Priestley, M. (2021). Curriculum reform in Scottish Education: Discourse, Narrative and Enactment. In: M. Priestley, D. Alvunger, S. Philippou. \& T. Soini, Curriculum making in Europe: policy and practice within and across diverse contexts. Bingley: Emerald.

eliminated. The ICEA produced an interim report in 2017 and a formal report in 2018. The 2017 report recommended improving pedagogy for specific subjects, unleashing untapped potential within the system and ensuring a culture of collaboration. The 2018 report reinforced the centrality of Curriculum for Excellence, describing it as "the cornerstone of educational transformation in Scotland" (ICEA, 2018, para. 6) and emphasising the need to retain its "vision and holistic approach" (ibid, para. 13). The report endorsed the shift from "coverage of defined subjects or areas" (ibid, para. 21) to a pedagogical approach which "sought to describe what young people should become as a result of their learning" (ibid, para. 21). This was a direct reference to the four capacities of CfE and perhaps implied that an over-emphasis on "successful learners" had led to insufficient attention being given to "confident individuals", "effective contributors" and "responsible citizens". Comparisons were drawn with similar reform programmes in other parts of the world and with the OECD's 2030 project (ibid, para. 22).

The ICEA report did not offer a detailed review of the extent to which CFE could be judged successful, but drew attention to the need to view curriculum change in relation to other policy initiatives, such as the National Improvement Framework (NIF) and Pupil Equity Funding (PEF), which sought to promote the twin aims of "excellence" and "equity". The NIF is designed to bring about improvements in attainment, particularly in literacy and numeracy, while PEF provides additional resources to support disadvantaged children, as part of a strategy to reduce the poverty-related "attainment gap". These initiatives have sometimes been described in terms of "delivering" improvements. The ICEA report cautions against the language of delivery and states that a "clear and consistent narrative of change" (ibid, para. 79) is needed: that narrative "should be founded on professional agency, empowerment, improvement, and change, and not premised on the technical terminology of delivery, reform and implementation" (ibid, para. 80).

An analysis of the language of the report is interesting, not only for what it contains but also for what is largely absent. The economic drivers of educational reform hardly feature at all: the word "skills" appears four times, "market" three, "employability" two and "employment" one. Even "knowledge" (8) and "subjects" (4) are not strongly represented. These low figures can be contrasted with a group of terms that constitute the dominant narrative thread: "culture" (40), "capacity-building)" (31), "collaboration" (28), "empowerment" (22), "partnership" (10), "trust" (10) and "ownership" (10). This collection of terms suggests that there is a significant challenge for Scottish education to create the right professional climate for teachers to feel confident that they can function effectively as curriculum developers and change agents. A few months after the ICEA appeared there was an article in the Times Educational Supplement Scotland reporting that a "culture of fear" still prevailed in Scottish 
Humes, W. \& Priestley, M. (2021). Curriculum reform in Scottish Education: Discourse, Narrative and Enactment. In: M. Priestley, D. Alvunger, S. Philippou. \& T. Soini, Curriculum making in Europe: policy and practice within and across diverse contexts. Bingley: Emerald.

education, discouraging teachers from speaking out about their concerns (Seith, 2018). One of the stated intentions of CfE was to encourage teachers to take more responsibility and exercise greater agency in their professional work. For many professionals, however, the rhetoric of empowerment fails to connect with the lived reality of teaching. It seems that there is still a great deal of work to be done in terms of enhancing capacity and changing cultures. As the ICEA report notes: "the language around the current educational improvement programme tends to be largely aspirational" (ICEA, 2018, para. 44).

Different levels of policy making (supra, macro, meso) are reflected in the ICEA report. At national level, the role of Education Scotland, the principal advisory body on the curriculum, now also responsible for school inspections and the work of the Scottish College for Educational Leadership, is recognized. So too are the 32 local authorities, which have statutory responsibility for the running of schools and the employment of teachers. An attempt to redefine the role of local authorities, seemingly giving more power directly to headteachers, met with opposition and the Scottish Government had to delay plans for governance reform. What did emerge, however, was the settingup of six Regional Improvement Collaboratives (RICs) designed to share expertise, establish collaborative networks and share best practice. These can be seen as a response to the call by the OECD in its 2015 report on Scottish education for "a strengthened middle operating through networks ... within and across local authorities . . to create coherent and cohesive cultures of system-wide improvement" (OECD, 2015: 15). The ICEA recognizes the potential of this development but stresses that it will be necessary to evaluate the evidence of their impact once they become established. Rather disappointingly, the interim report of the RICs published in 2019 had nothing to say about curriculum reform (Scottish Government, 2019a), and emerging anecdotal evidence suggests that they continue to have a strong focus on measurement of performance and evaluation of initiatives (a replication of local authority functions that emphasizes outputs), perhaps neglecting a support function that develops the quality inputs necessary to foster meaningful engagement with curricular issues. The ICEA report seems to recognize this tension, stressing the point that the output from the RICs should be "contextually nuanced and contextually embedded" (ICEA, 2018, para. 45), implying that effective curriculum reform must arise from and relate to local circumstances and not simply respond to central directives. This is consistent with one of the conclusions of the study by Priestley and Minty cited earlier:

Agency is ecological; agents act by means of their environment, so the achievement of agency strongly depends on cultural (meaning, interpretation and understanding), structural (relationships, power) and material resources. The promotion of teacher agency is therefore 
Humes, W. \& Priestley, M. (2021). Curriculum reform in Scottish Education: Discourse, Narrative and Enactment. In: M. Priestley, D. Alvunger, S. Philippou. \& T. Soini, Curriculum making in Europe: policy and practice within and across diverse contexts. Bingley: Emerald.

not solely a matter of enhancing individual capacity, but also requires change to the cultural and structural conditions within which teachers work (Priestley \& Minty, 2013: 50).

It was noted above that the political, economic and technological drivers of global educational reform do not feature strongly in the discourse of the ICEA report. Furthermore, it advises that the Scottish system "should not be seduced by some of the perceived advantages of other systems, or borrow strategies that would not sit easily with the core values and beliefs that underpin the Scottish education system and wider civic society" (ibid, para. 105). All stakeholders should be encouraged to reflect on "the established/historical culture of Scottish education" (ibid, para 93) and consider which aspects need to be enhanced or changed. It is a reasonable ambition to make Scottish education "world-leading" but it should remain "uniquely and appropriately Scottish" (ibid, para.52). Scotland has a distinguished educational tradition. The challenge is to remain true to the best aspects of that tradition while projecting a positive and forward-looking international outlook. To what extent does the latest iteration of Curriculum for Excellence address that challenge?

\section{A "refreshed" CfE Narrative (2019)}

The 2015 OECD report stated that it could not offer a full evaluation of the success of CFE because there was insufficient data on which to form a judgement. Instead, it presented a "review", noting strengths and weaknesses and recommending that a "new narrative" of the reform should be developed (OECD, 2015). Four years later, such a narrative was produced following extensive consultation with a range of stakeholders (national bodies, local authorities, teachers' organizations, parental representatives $)^{7}$. The updated version is not a change to the substantive curriculum. Instead it seeks to "revisit the initial Curriculum for Excellence ( $\mathrm{CFE}$ ) narrative and set it within the current context" (Scottish Government, 2019b). That context included the establishment in 2017 of a Curriculum and Assessment Board ( $C A B)$ as part of the national governance structure of education in Scotland. The refreshed narrative was commissioned and overseen by CAB.

The narrative has two stated purposes:

1. It is a single point of entry for practitioners engaging with $\mathrm{CFE}$, providing links to pertinent documents. This addresses criticisms of the difficulties encountered by practitioners seeking to decide which documentation is relevant or not to their curriculum making.

\footnotetext{
${ }^{7}$ The narrative is online at https://scotlandscurriculum.scot/
} 
Humes, W. \& Priestley, M. (2021). Curriculum reform in Scottish Education: Discourse, Narrative and Enactment. In: M. Priestley, D. Alvunger, S. Philippou. \& T. Soini, Curriculum making in Europe: policy and practice within and across diverse contexts. Bingley: Emerald.

2. Significantly, and representing a new direction within $\mathrm{CFE}$, it provides a process for engaging with CfE, framed around "why" questions (positioning purposes as a starting point for engagement), "what" questions and "how" questions.

It is available only in digital form and uses an interesting mixture of graphic presentation and text: "pop-up" boxes give access to short elaborations of "headline" items, and there are links to key resources on other websites. This approach represents a response to criticism of excessive documentation at earlier stages of the reform process. The content contains elements of both continuity and change. The former is evident in the restatement of the four capacities, in the contexts for learning (curriculum areas, personal achievement, school ethos and interdisciplinary learning) and in the emphasis on skills (for learning, life and work). Change is signalled in the use of new terminology, notably "curriculum making", "teacher agency" and "meta-skills". The first two terms, which are undefined within the "refreshed" narrative, can be seen as an acknowledgement of the intellectual challenge involved in curriculum reform, the need to provide scope for engagement with fundamental principles and opportunities for teachers to develop confidence in making curricular decisions appropriate to the particular contexts in which they work. In explaining "meta-skills", a link is provided to the organization Skills Development Scotland which has a particular focus on future employability: one of its publications identifies "self-management", "social intelligence" and "innovation" as essential requirements in adapting to economic and technological change (Skills Development Scotland, 2018). These qualities can be seen as an acknowledgement of the wider international context within which all advanced educational systems now have to operate.

It is too early to say how helpful the refreshed narrative of CfE will prove to be to practitioners in schools, although it has been well-received in consultations. It certainly represents a simplification of the key messages of the original reform, together with some pointers towards how the expertise of teachers might be more effectively mobilized in translating conception into practice. But whether this will be sufficient to create the necessary climate of trust between policy makers and practitioners, to allow genuine partnership between the various agencies involved, and to make inroads into the traditionally hierarchical and conformist culture of Scottish education, remains uncertain.

\section{Curriculum making across the system}

In the light of the above discussion, we next reflect briefly on the curriculum making that has occurred across the different layers of the Scottish education system. We acknowledge here that the 
Humes, W. \& Priestley, M. (2021). Curriculum reform in Scottish Education: Discourse, Narrative and Enactment. In: M. Priestley, D. Alvunger, S. Philippou. \& T. Soini, Curriculum making in Europe: policy and practice within and across diverse contexts. Bingley: Emerald.

boundaries between macro-, meso- and micro-layers of curriculum making are fluid and porous, and often difficult to delineate. For that reason, we prefer to see them not as hard and fast institutional levels, but rather as layers of different kinds of activity. Thus, the macro-layer relates to the production of official curriculum texts - statements of intent - and corresponds with Bernstein's (1996) notion of the official recontextualization field. This function was undertaken in Scotland by both the Scottish Government, and latterly by Education Scotland. The meso-layer is concerned with the production of guidance and exemplification - often recontextualized further - and support for curriculum making. In Scotland this has traditionally taken the form of guidance produced by Education Scotland, its predecessors, and local authorities, but has been recently supplemented by the formation of the six RICs. The micro-layer relates to the development of the curriculum in schools and classrooms.

\section{Macro}

Macro-level curriculum making occurred in several waves in respect of CfE. Initial discussion documents produced by the government, were followed by the Building the Curriculum Series along with specification of learning outcomes - the Experiences and Outcomes. Subsequently, official documentation included the 2016 Statement for Practitioners and the assessment benchmarks, and the more recent refreshed narrative (although we note that this latter development is "officially" not a government or Education Scotland initiative, but rather an artefact produced in partnership by stakeholders). It is possible to discern discursive and substantive shifts in emphasis over time. Early documentation emphasizes the developmental nature of the curriculum, and the importance of core purposes. Subsequently, focus fell more narrowly on the Experiences and Outcomes, which morphed from being desiderata into assessment standards (Priestley, 2013). The 2016 development of assessment benchmarks appears to have solidified this drift towards an assessment driven curriculum. Other substantive changes concern an increased emphasis over time on issues such as literacy, numeracy, health and well-being and equity. Most recently, a shift back to a focus on the purposes (or big ideas) of the curriculum has been evident, as encapsulated in the Four Capacities, and there has been a distinct renewed emphasis on the agentic role of practitioners as curriculum makers, reflected particular in the recourse to previously unused concepts such as curriculum making and teacher agency.

Meso

There have also been overt changes of emphasis in relation to the meso-level activity that supports curriculum making in schools. In the early days of $\mathrm{CfE}$, the main emphasis was on the specification of outcomes and associated performance indicators, and a focus on evaluation methodologies as a proxy 
Humes, W. \& Priestley, M. (2021). Curriculum reform in Scottish Education: Discourse, Narrative and Enactment. In: M. Priestley, D. Alvunger, S. Philippou. \& T. Soini, Curriculum making in Europe: policy and practice within and across diverse contexts. Bingley: Emerald.

for curriculum development (including external inspections and local authority quality audits). These techniques were accompanied by the production of reams of exemplification - the sharing of so-called "best practice". While the abovementioned approaches have not been abandoned, they have certainly decreased in intensity and scale. In particular, Education Scotland has removed a great deal of superfluous guidance from its website. Instead there is a renewed focus on developing quality inputs. The new RICs, while at an early stage of development, promise to provide a new infrastructure to provide support and leadership for curriculum making in schools, and many local authorities are providing support to develop the curriculum. Underpinning these initiatives is a renewed focus on teacher professional learning, often conducted through methodologies of collaborative professional enquiry (e.g. see: Priestley and Drew, 2017), particularly via funded Master's level study and leadership courses provided via the former Scottish College for Educational Leadership (SCEL, now assimilated into Education Scotland).

Micro

Of course, the true test of whether a curriculum reform has been successful lies in the extent to which meaningful practices have developed in schools - the enacted curriculum developed by teachers and the received curriculum experienced by students. On balance, CfE has not significantly affected this, at least in a coherent way that reflects the intentions set out in the official curriculum, and much progress remains to be made. As the OECD's Andreas Schleicher stated in 2016, Scotland needs to move from an intended curriculum to an implemented curriculum ${ }^{8}$. There is evidence that the early phase of the curriculum - both in terms of early adopter schools prior to 2010 and across the system following the mandated roll out of the reforms in 2011 - was largely characterized by an audit approach to curriculum making; this primarily involved ticking off current practice against the Experiences and Outcomes, and tweaking practices to accommodate the new curriculum (Priestley and Minty, 2013). Many teachers appear to have adopted the new terminology of policy to describe existing practices (Priestley et al., 2015). In both cases, reform was often minimal and/or tokenistic. In many primary schools, a prevailing attitude has been that "we are doing this already". Secondary schools have tended to frame CfE as implementation of new qualifications. Since 2018 , there has been a renewed emphasis on revisiting the core principles of CfE. Subsequently, there has been a push for schools to develop a curriculum rationale, and for secondary schools to focus more on the S1 to S3 Broad General Education phase. Interestingly, the concept curriculum has re-entered professional discourse in a more systematic way than previously, as evidenced by the development of the refreshed

\footnotetext{
${ }^{8}$ BBC news, December 2016
} 
Humes, W. \& Priestley, M. (2021). Curriculum reform in Scottish Education: Discourse, Narrative and Enactment. In: M. Priestley, D. Alvunger, S. Philippou. \& T. Soini, Curriculum making in Europe: policy and practice within and across diverse contexts. Bingley: Emerald.

CfE narrative, and by a new prevalence of professional learning with a curriculum focus. There is a sense that meaningful curriculum making is back on the menu in Scottish schools and this may bode well for the future development of CfE.

\section{Conclusions}

Nevertheless, despite the positive note sounded above, curriculum making in Scotland remains challenging. From the beginning, CfE sought to put the learning of children and young people at the heart of the reform. This is an admirable aim, but it is instructive to ask what have policy makers and professionals themselves learned from the experience of trying to translate vision into reality. There are several ways in which this question might be addressed. One approach would be to focus on the conceptual coherence of the original proposals, the extent to which they drew on existing knowledge about curriculum models. The evidence suggests that, certainly in the early stages, there was a reluctance to engage with challenging theoretical issues and to draw on the substantial body of academic literature that existed (Priestley \& Humes, 2010). A second line of investigation would look at the language of reform and the consistency of the narratives designed to promote change. The choice of the word "excellence" in the title of the programme was a high-stakes decision, which carried the risk of embarrassment when concerns subsequently arose about standards in Scottish education. Statements by politicians about the "delivery" and "implementation" of CfE have revealed a lack of understanding of the complexity of curriculum making. An assessment of the institutional effectiveness of bodies charged with promoting the policy, and ensuring that local authorities and schools were adequately prepared, represents a third source of learning about the process of reform. As noted above, at certain points the exercise became cumbersome and over-bureaucratic and led to complaints about teachers being burdened with an excessive amount of documentation. A fourth line of enquiry could examine the adequacy of the data gathered to provide evidence about the how the reform was proceeding. Until a late stage, there seemed to be resistance on the part of government to commission any independent evaluation of what was happening. But perhaps the most fundamental issue of all is the gap between intention and enactment, including how teachers responded to the initiative and how it impacted on their sense of professional identity. Initial support for the broad principles of CfE (including the four capacities) was gradually overtaken by frustration about the perceived lack of clarity in some of the key concepts (such as interdisciplinary learning), by anxiety about the delay in announcing changes in assessment to accompany the new curriculum, and by uncertainly about their role as "empowered" curriculum developers within a transformed culture. 
Humes, W. \& Priestley, M. (2021). Curriculum reform in Scottish Education: Discourse, Narrative and Enactment. In: M. Priestley, D. Alvunger, S. Philippou. \& T. Soini, Curriculum making in Europe: policy and practice within and across diverse contexts. Bingley: Emerald.

That is why the recent focus on "sense making" and teacher agency is so important (Priestley et al, 2015). Effective and sustainable curriculum development has to win the hearts and minds of teachers, and the organizations which require them to introduce changes must inspire confidence and trust.

Add to all of these elements the continuing pressures coming from the "supra" level of policy making (economic and technological drivers, multi-national companies seeking a workforce with flexible skills rather than formal knowledge, international agencies producing reports which encourage convergent educational thinking) and disentangling the various layers of influence becomes highly problematic. It is possible that curriculum making will remain an elusive (and perhaps contested) concept for some time to come.

\section{References}

Ball, S. J. (1990) Politics and Policy Making in Education. London: Routledge.

Ball, S. J. (2012) Global Education Inc.. London: Routledge.

Ball, S. J., Maguire, M. \& Braun, A. (2012) How Schools Do Policy: Policy Enactments in Secondary Schools. London: Routledge.

Bernstein, B. (1996) Pedagogy, symbolic control and identity: theory, research, critique. London: Rowman and Littlefield Publishers.

Blackburn, L. H. \& McEnaney, J. (2017) Critical - or complaisant - friends on education. Sceptical Scot: http://sceptical.scot/2017/02/4771/

Broadhead, P. (2002) The Making of a Curriculum: how history, politics and personal perspectives shape emerging policy and practice, Scandinavian Journal of Educational Research, 46 (1): 47 $\underline{64 .}$

Donaldson, G. (2014) Teacher Education and Curriculum Change in Scotland, European Journal of Education, 49 (2), 178-190.

Education Scotland (2016) Curriculum for Excellence: A Statement for Practitioners from HM Chief Inspector of Education. Livingston: Education Scotland.

Gatherer, W. A. (1989) Curriculum Development in Scotland. Edinburgh: Scottish Academic Press.

Hizli Alkan, S. \& Priestley, M. (2019). Teacher mediation of curriculum making: the role of reflexivity. Journal of Curriculum Studies, 51 (5), 737-754.

Humes, W. (2013) The Origins and Development of Curriculum for Excellence: Discourse, Politics and Control, in M. Priestley \& G. Biesta (Eds.), Reinventing the Curriculum: New Trends in Curriculum Policy and Practice (pp. 13-34). London: Bloomsbury.

Humes, W. \& Bryce, T. (2018) The Distinctiveness of Scottish Education, in T. G. K. Bryce, W. M. Humes, D. Gillies \& A. Kennedy (Eds), Scottish Education, $5^{\text {th }}$ edition (pp. 118-128). Edinburgh: Edinburgh University Press.

International Council of Education Advisers (2018) Report 2016-18. Edinburgh: Scottish Government.

Kidner, C. (2010) Curriculum for Excellence: SPICe Briefing. Edinburgh: The Scottish Parliament. http://www.parliament.scot/Research\%20briefings\%20and\%20fact\%20sheets/SB10-10.pdf

Organisation for Economic Cooperation and Development (OECD) (2007) Quality and Equity of Schooling in Scotland. Paris: OECD.

Organisation for Economic Cooperation and Development (OECD) (2015) Improving Schools in Scotland: An OECD Perspective. Paris: OECD. 
Humes, W. \& Priestley, M. (2021). Curriculum reform in Scottish Education: Discourse, Narrative and Enactment. In: M. Priestley, D. Alvunger, S. Philippou. \& T. Soini, Curriculum making in Europe: policy and practice within and across diverse contexts. Bingley: Emerald.

Organisation for Economic Cooperation and Development (OECD) (2015) The Future of Education and Skills: Education 2030. Paris: OECD.

Priestley, M (2013). The 3-18 Curriculum in Scottish Education. In: Bryce, T.G.K., Humes, W.M. Gillies, D. \& Kennedy, A., (Eds.), Scottish Education, 4th edition, Referendum (pp 28-38). Edinburgh: Edinburgh University Press.

Priestley, M. (2016) A Statement for Practitioners: how useful is the new CfE guidance? https://mrpriestley.wordpress.com/2016/08/

Priestley, M. (2018a) Curriculum Reform: Progress, Tensions and Possibilities, in T. G. K. Bryce et al, (Eds), Scottish Education, $5^{\text {th }}$ edition (pp. 897-907). Edinburgh: Edinburgh University Press.

Priestley, M. (2018b) Is Scotland's curriculum really narrowing? Times Educational Supplement, 27 September, 2018. https://www.tes.com/news/scotlands-curriculum-really-narrowing

Priestley, M. \& Biesta, G. (Eds) (2013) Reinventing the Curriculum: New Trends in Curriculum Policy and Practice. London: Bloomsbury.

Priestley, M. \& Drew, V. (2017) Teacher Sense-Making in School-Based Curriculum Development Through Critical Collaborative Professional Enquiry, in M. Peters, B. Cowie \& I. Menter (Eds.), A Companion to Research in Teacher Education, pp. 769-783. Singapore: Springer.

Priestley, M. \& Humes, W. (2010) The development of Scotland's Curriculum for Excellence: amnesia and déjà vu, Oxford Review of Education, 36(3), 23-36.

Priestley, M., Minty, S. \& Eager, M. (2013) School-based Curriculum Development in Scotland: curriculum policy and enactment, Pedagogy, Culture and Society, 22 (2): 189-211.

Priestley, M., Biesta, G. \& Robinson, S. (2015) Teacher Agency: An Ecological Approach. London: Bloomsbury.

Priestley, M. \& Philippou, S. (2018) Curriculum making as social practice: complex webs of enactment, Curriculum Journal, 29 (2), 151-158.

Reeves, J. (2008) Between a rock and a hard place? Curriculum for Excellence and the quality initiative in Scottish Schools, Scottish Educational Review, 40 (2): 6-16.

Raffe, D. (2008). As others see us: a commentary on the OECD review of the quality and equity of schooling in Scotland. Scottish Educational Review, 40[1], 22-36.

Roger, A. \& Hartley, D. eds. (1990) Curriculum and Assessment in Scotland: A Policy for the 1990s. Edinburgh: Scottish Academic Press.

Scottish Executive (2004) A Curriculum for Excellence: The Curriculum Review Group. Edinburgh: Scottish Executive.

Scottish Executive (2006a) A Curriculum for Excellence: Progress and Proposals. Edinburgh: Scottish Executive.

Scottish Executive (2006b) Building the Curriculum 1: The Contribution of Curricular Areas. Edinburgh: Scottish Executive.

Scottish Executive (2007) Building the Curriculum 2: Active Learning in the Early Years. Edinburgh: Scottish Executive.

Scottish Government (2008) Building the Curriculum 3: A Framework for Learning and Teaching. Edinburgh: Scottish Government.

Scottish Government (2009) Building the Curriculum 4: Skills for Learning, Skills for Life and Skills for Work. Edinburgh: Scottish Government).

Scottish Government (2011) Building the Curriculum 5: A Framework for Assessment. Edinburgh: Scottish Government.

Scottish Government (2016) National Improvement Framework for Scottish Education. Edinburgh: Scottish Government.

Scottish Government (2019a) Regional Improvement Collaboratives (RICs): Interim Review. Edinburgh: Scottish Government.

Scottish Government (2019b) Scotland's Curriculum for Excellence: Putting Learners at the Heart of Education. https://scotlandscurriculum.scot/ 
Humes, W. \& Priestley, M. (2021). Curriculum reform in Scottish Education: Discourse, Narrative and Enactment. In: M. Priestley, D. Alvunger, S. Philippou. \& T. Soini, Curriculum making in Europe: policy and practice within and across diverse contexts. Bingley: Emerald.

Seith, E. (2018) 'Teachers are too afraid to speak out', Times Educational Supplement Scotland, No. 2602: 14-19.

Shapira, M. \& Priestley, M. (2018) Narrowing the Curriculum? Contemporary Trends in Provision and Attainment in the Scottish Curriculum, Scottish Educational Review, 50 (1), 75-107.

Shapira, M. \& Priestley, M. (2019). Do schools matter? An exploration of the determinants of lower secondary school subject choices under the Scottish Curriculum for Excellence. Review of Education, 191-238.

Sinnema, C., \& Aitken, G. (2013). Emerging International Trends in Curriculum. In M. Priestley \& G. J. J. Biesta (Eds.), Reinventing the Curriculum: New Trends in Curriculum Policy and Practice pp.141-164). London: Bloomsbury Academic

Skills Development Scotland (2018) Skills 4.0: A Skills Model to Drive Scotland's Future. Glasgow: Skills Development Scotland.

Wolf, A. (1995) Competence-Based Assessment. Buckingham: Open University Press 